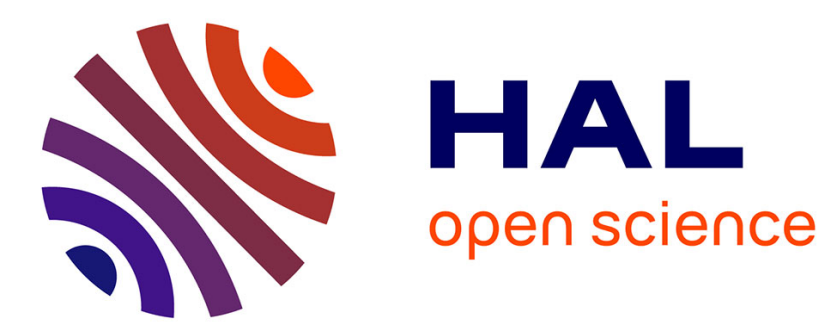

\title{
Latitudinal gradient of nestedness and its potential drivers in stream detritivores
}

Luz Boyero, Richard G. Pearson, Christopher M. Swan, Cang Hui, Ricardo J. Albariño, Muthukumarasamy Arunachalam, Marcos Callisto, Julián Chará, Ana M. Chará-Serna, Eric Chauvet, et al.

\section{To cite this version:}

Luz Boyero, Richard G. Pearson, Christopher M. Swan, Cang Hui, Ricardo J. Albariño, et al.. Latitudinal gradient of nestedness and its potential drivers in stream detritivores. Ecography, 2015, vol. 38 (n 8), pp. 1-7. 10.1111/ecog.00982 . hal-01187241

\section{HAL Id: hal-01187241 \\ https://hal.science/hal-01187241}

Submitted on 26 Aug 2015

HAL is a multi-disciplinary open access archive for the deposit and dissemination of scientific research documents, whether they are published or not. The documents may come from teaching and research institutions in France or abroad, or from public or private research centers.
L'archive ouverte pluridisciplinaire HAL, est destinée au dépôt et à la diffusion de documents scientifiques de niveau recherche, publiés ou non, émanant des établissements d'enseignement et de recherche français ou étrangers, des laboratoires publics ou privés. 


\section{OATAO}

\section{Open Archive TOULOUSE Archive Ouverte (OATAO)}

OATAO is an open access repository that collects the work of Toulouse researchers and makes it freely available over the web where possible.

This is an author-deposited version published in : http://oatao.univ-toulouse.fr/ Eprints ID : 14200

To link to this article : DOI:10.1111/ecog.00982

URL : http://dx.doi.org/10.1111/ecog.00982

To cite this version : Boyero, Luz and Pearson, Richard G. and Swan, Christopher M. and Hui, Cang and Albariño, Ricardo J. and Arunachalam, Muthukumarasamy and Callisto, Marcos and Chará, Julián and Chará-Serna, Ana M. and Chauvet, Eric and Cornejo, Aydeé and Dudgeon, David and Encalada, Andrea C. and Ferreira, Verónica and Gessner, Mark O. and Gonçalves, José F. and Graça, Manuel A. S. and Helson, Julie E. and Mathooko, Jude M. and McKie, Brendan G. and Moretti, Marcelo S. and Yule, Catherine M.

Latitudinal gradient of nestedness and its potential drivers in stream detritivores. (2015) Ecography, vol. 38 (n 8). pp. 1-7. ISSN 09067590

Any correspondance concerning this service should be sent to the repository administrator: staff-oatao@,listes-diff.inp-toulouse.fr 


\title{
Latitudinal gradient of nestedness and its potential drivers in stream detritivores
}

\author{
Luz Boyero, Richard G. Pearson, Christopher M. Swan, Cang Hui, Ricardo J. Albariño, \\ Muthukumarasamy Arunachalam, Marcos Callisto, Julián Chará, Ana M. Chará-Serna, \\ Eric Chauvet, Aydeé Cornejo, David Dudgeon, Andrea C. Encalada, Verónica Ferreira, \\ Mark O. Gessner, José F. Gonçalves Jr, Manuel A. S. Graça, Julie E. Helson, Jude M. Mathooko, \\ Brendan G. McKie, Marcelo S. Moretti and Catherine M. Yule
}

\begin{abstract}
L. Boyero (luz.boyero@ehu.es),Faculty of Science and Technology, Univ. of the Basque Country (UPVIEHU), Leioa, Spain, and IKERBASQUE, Basque Foundation for Science, Bilbao, Spain, and Wetland Ecology Dept, Doñana Biological Station-CSIC, Av. Americo Vespucio s/n, ES-41092 Sevilla, Spain. - R. G. Pearson and LB, School of Marine and Tropical Biology and TropWater, James Cook Univ., Townsville, QLD 4811, Australia. - C. M. Swan, Dept of Geography and Environmental Systems, Univ. of Maryland, Baltimore County, Baltimore, MD 21250, USA. - C. Hui, Centre for Invasion Biology, Dept of Mathematical Sciences, Univ. of Stellenbosch, Private Bag X1, Matieland 7602, South Africa, and African Inst. for Mathematical Sciences, Muizenburg 7945, South Africa. - R. J. Albariño, Laboratorio de Fotobiologia, INIBIOMA, Univ. Nacional del Comahue-CONICET, Quintral 1250, 8400, Argentina. - M. Arunachalam, Sri Paramakalyani Centre for Environmental Sciences, Manonmainam Sundaranar Univ., Alwarkuruchi, Tamil Nadu 627 412, India. - M. Callisto, Laboratório de Ecologia de Bentos, Inst. de Ciências Biológicas, Univ. Federal de Minas Gerais, CP 486, CEP 30.161-970, Belo Horizonte, MG, Brazil. - J. Chará and A. M. Chará-Serna, Centro para la Investigación en Sistemas Sostenibles de Producción Agropecuaria, CIPAV, Carrera 25 no. 6-62, Cali, Colombia. JC also at: Centro de Investigaciones y Estudios en Biodiversidad y Recursos Genéticos, CIEBREG, POB 97, Pereira, Colombia. AMC-S also at: Dept of Forest Sciences, Univ. of British Columbia, 3621-2424 Main Mall, Vancouver, BC V6T 1Z4, Canada. - E. Chauvet, Univ. de Toulouse, UPS, INPT, EcoLab (Laboratoire d'Écologie Fonctionnelle et Environnement), 29 Rue Jeanne Marvig, FR-31055 Toulouse, France, and CNRS, EcoLab, FR-31055 Toulouse, France. - A. Cornejo, Colección Zoológica Dr. Eustorgio Mendez, Inst. Conmemorativo Gorgas de Estudios de la Salud, Avenida Justo Arosemena and Calle 35, 0816-02593 Panama City, Panama. - D. Dudgeon, School of Biological Sciences, The Univ. of Hong Kong, Hong Kong SAR, China. - A. C. Encalada, Colegio de Ciencias Biológicas y Ambientales, Univ. San Francisco de Quito, Campus Cumbayá, PO Box 17-1200-841, Quito, Ecuador. - V. Ferreira, M. A. S. Graça and ACE, IMAR-CMA and Dept of Life Sciences, Univ. of Coimbra, PT-3001-401 Coimbra, Portugal. - M. O. Gessner, Dept of Experimental Limnology, Leibniz Inst. of Freshwater Ecology and Inland Fisheries (IGB), Alte Fischerhütte 2, DE-16775 Stechlin, Germany, and Dept of Ecology, Berlin Inst. of Technology (TU Berlin), Ernst-Reuter-Platz 1, DE-10587 Berlin, Germany. - J. F. Gonçalves Jr, Laboratório de Limnologia, Depto de Ecología, IB, Univ. de Brasilia, CEP 70910-900, Brasilia, DF, Brazil. - J. E. Helson, Surface and Groundwater Ecology Research Group, Dept of Biological Sciences, Univ. of Toronto at Scarborough, 1265 Military Trail, Toronto, ON M1C1A4, Canada. - J. M. Mathooko, Dept of Biological Sciences, Egerton Univ., PO Box 536, Egerton, Kenya. - B. G. McKie, Dept of Aquatic Sciences and Assessment, Swedish Univ. of Agricultural Sciences, SE-75007 Uppsala, Sweden. - M. S. Moretti, Laboratory of Aquatic Insect Ecology, Univ. of Vila Velha, Av. Comissário José Dantas de Melo 21, 29.102-920, Vila Velha, Brazil. - C. M. Yule, School of Science, Monash Univ., Jalan Lagoon Selatan, Bandar Sunway, 46150, Selangor, Malaysia.
\end{abstract}

Understanding what mechanisms shape the diversity and composition of biological assemblages across broad-scale gradients is central to ecology. Litter-consuming detritivorous invertebrates in streams show an unusual diversity gradient, with $\alpha$-diversity increasing towards high latitudes but no trend in $\gamma$-diversity. We hypothesized this pattern to be related to shifts in nestedness and several ecological processes shaping their assemblages (dispersal, environmental filtering and competition). We tested this hypothesis, using a global dataset, by examining latitudinal trends in nestedness and several indicators of the above processes along the latitudinal gradient. Our results suggest that strong environmental filtering and low dispersal in the tropics lead to often species-poor local detritivore assemblages, nested in richer regional assemblages. At higher latitudes, dispersal becomes stronger, disrupting the nested assemblage structure and resulting in local assemblages that are generally more species-rich and non-nested subsets of the regional species pools. Our results provide evidence that mechanisms underlying assemblage composition and diversity of stream litter-consuming detritivores shift across latitudes, and provide an explanation for their unusual pattern of increasing $\alpha$-diversity with latitude. When we repeated these analyses for whole invertebrate assemblages of leaf litter and for abundant taxa showing reverse or no diversity gradients we found no latitudinal patterns, suggesting that function-based rather than taxon-based analyses of assemblages may help elucidate the mechanisms behind diversity gradients. 
Explaining what mechanisms shape the diversity and composition of biological assemblages and how these vary at broad scales are central goals of ecology. One of the most striking and best documented patterns on earth is the latitudinal gradient of regional diversity $(\gamma)$ which, for many taxa, peaks in tropical regions and shows a steady decline towards the poles (Pianka 1966, Hillebrand 2004). This pattern in $\gamma$-diversity can sometimes explain latitudinal patterns in the diversity of local assemblages $(\alpha)$ and their compositional turnover $(\beta)$, suggesting that similar ecological mechanisms might be operating at different latitudes (Kraft et al. 2011). However, this is not always the case, and ecological mechanisms underlying diversity gradients are not yet well understood, with most hypotheses still untested (Willig et al. 2003).

Litter-consuming detritivorous invertebrates in streams (hereafter 'detritivores') show contrasting patterns of $\alpha$ - and $\gamma$-diversity across latitudes (Boyero et al. 2012) and thus offer an opportunity for examining the above questions. While there are more detritivore species locally at higher than lower latitudes (i.e. they show a 'reversed' or positive latitudinal gradient for $\alpha$-diversity), their regional species pools do not change systematically with latitude (Boyero et al. 2011a). It is thus plausible that detritivore assemblages are structured differently at different latitudes, with variation in the relative importance of different ecological processes shaping their assemblages. Here we use a global dataset to examine this question through the analysis of latitudinal gradients in assemblage nestedness and in several indicators of potentially relevant ecological processes, namely dispersal, environmental filtering and competition. Nestedness is an informative measure relating to relationships among, and structure of contiguous and separated assemblages. is complementary to other measures such as species turnover ( $\beta$-diversity) that we have reported for the assemblages studied here (Boyero et al. 2012). There is, to our knowledge, no information on how nestedness varies with latitude, although this metric is an important proxy for the resilience and robustness of ecosystems against environmental change (Bascompte et al. 2003), which has clear implications for conservation.

Nestedness occurs when the species present at less species-rich sites are subsets of the assemblages of richer sites (Wright and Reeves 1992, Ulrich et al. 2009). The few species present at poorer sites are those that are found everywhere, whereas only richer sites will support the more uncommon species (Wright and Reeves 1992). For detritivores, we suggest that many tropical sites are relatively species poor because they are nested subsets of richer assemblages, as can be the case for terrestrial vertebrates (Williams and Pearson 1997). That is, we hypothesise (H1) that the nestedness of detritivore assemblages is higher towards the tropics, and that this pattern is the result of a combination of the following patterns.

1) Lower dispersal capabilities towards the tropics (H2). It has been shown for other organisms (e.g. woody plants) that nestedness can be caused by low dispersal (Kadmon 1995). We suggest that detritivore dispersal could be lower in the tropics because, following Janzen's (1967) hypothesis, localities at different altitudes show little overlap in climate, due to their low seasonality, so species have relatively narrow temperature tolerances that limit altitudinal range shifts.
2) Stronger environmental filtering towards the tropics (H3), as seen in some tropical vertebrate assemblages (Williams and Pearson 1997). As many detritivores have evolved in cool waters, higher temperatures may limit their distribution for physiological reasons (Boyero et al. 2011a). Also, a less variable climate promotes greater climatic specialisation (Kozak and Wiens 2007), and filtering would be expected to affect specialists more than generalists. While generalists would have a widespread distribution, specialists would only occupy sites with few filters (Boyero et al. 2011b, Chase and Myers 2011, Hui et al. 2013).

3) Weaker interspecific competition towards the tropics (H4). A nested structure may reduce effective interspecific competition because specialists interact only with subsets of the species that interact with the generalists (Bastolla et al. 2009). Thus we predict that there would be evidence of less competition in the tropics, although this might be countered by competition for good-quality leaf litter resources, which are generally scarcer in the tropics (Boyero et al. 2006, 2011a, Bastian et al. 2008).

Finally, we undertook similar analyses for whole invertebrate assemblages of leaf litter and for four abundant insect orders, which show reverse or no latitudinal diversity gradients (Supplementary material Appendix 1; Vinson and Hawkins 2003, Pearson and Boyero 2009). We suggest that previous studies failed to identify relationships between ecological processes and diversity across broad gradients because they focused on taxonomic groups. Species within taxa often use varied resources and interact variously, such that different ecological mechanisms operate simultaneously and, possibly, in different directions, obscuring patterns of occurrence. To this end, grouping species according to their functional role in ecosystems and examining how species within the same functional group respond collectively to broad gradients could be helpful. We thus hypothesise (H5) that any latitudinal gradients in nestedness, dispersal, environmental filtering and competition demonstrated for the detritivore functional group will not be found for whole assemblages or particular taxa of invertebrates inhabiting leaf litter.

\section{Material and methods}

\section{Study organisms}

There are two main types of detritivorous invertebrate guilds in streams: litter-consuming detritivores (which are often identical with 'shredders'), and fine-particle 'collectors' (Cummins and Klug 1979, Ramírez and Gutiérrez-Fonscca 2014). We studied litter-cosuming detrivores but refer to them as 'detritivores' for simplicity and analogy with terrestrial systems. Detritivores comprise many species of invertebrate taxa (in our dataset, 154 morphospecies belonging to at least 11 orders, mostly insect larvae with terrestrial adult stages - Supplementary material Appendix 1) that are important components of stream ecosystems and participants in land-water interactions (Wallace et al. 1997, Gessner et al. 2010). Detritivores assimilate carbon and nutrients from leaf litter and other plant detritus and, through their feeding activity, fragment the litter into fine organic particles that are subsequently ingested by invertebrate collectors which, in turn, are consumed by aquatic and terrestrial predators (Heard 1994). 


\section{Field and laboratory methods}

We sampled leaf litter from 149 stream sites in 15 regions across the globe covering a latitudinal range of $108^{\circ}$ (Fig. 1a, b; Table 1). Sampling grain was consistent across regions. Mean geographic distance was not correlated with latitude $(\mathrm{r}=0.31$, $\mathrm{p}=0.26$ ). Regions were not the same size, but 1 st order jackknife estimates indicated that, on average, $88 \%$ of species were recorded (Supplementary material Appendix 1, Table A1), and the $\%$ of species recorded was not correlated with latitude $(r=0.006, p=0.79)$. Each site was located in a different headwater stream with no notable direct human impact and all were similar in size (stream width $\leq 10 \mathrm{~m}$; site length $\approx 10$ times the stream width, ranging from 50 to $100 \mathrm{~m}$ ) and morphology (typical riffle-pool sequence). Details of sampling methods are given in Boyero et al. (2012; 13 regions), Swan et al. (2009; Maryland, USA), and McKie and Malmqvist (2009; Sweden).

We identified and counted all invertebrates found in the samples, and classified each morphospecies (i.e. morphologically distinct, if undescribed, taxa) as litter-consuming detritivore or non-detritivore based on gut content analysis and local specialists' knowledge (Boyero et al. 2011a, 2012). Taxonomic expertise was similar across regions so inconsistent accuracy in diversity estimates was unlikely. At each site we recorded latitude and altitude ( $\mathrm{m}$ a.s.l.) and measured the following environmental variables: leaf litter quantity (g dry mass in each sample), diversity (number of species in each sample) and prevalence (\% of substrate covered by leaf litter); riparian cover (\%) and diversity (number of woody plant species); \% native forest in the watershed and watershed area $\left(\mathrm{km}^{2}\right)$; stream channel width $(\mathrm{m})$, median water depth $(\mathrm{cm})$ and prevalence of pool habitats $(\%)$; water temperature $\left({ }^{\circ} \mathrm{C}\right)$, $\mathrm{pH}$, conductivity $\left(\mu \mathrm{Sm}^{-1}\right)$, alkalinity $\left(\mathrm{mg} \mathrm{CaCO}_{3} \mathrm{l}^{-1}\right)$, dis- solved oxygen concentration ( $\mathrm{mg} \mathrm{l}^{-1}$ ), and concentrations of total nitrogen, nitrate and nitrite, total phosphorus, and soluble reactive phosphorus (all in $\mathrm{mg} \mathrm{l}^{-1}$ ). Not all variables were measured at all sites, but the number and type of variables measured were not related to latitude. Mean environmental distance was not related to latitude $(\mathrm{r}=0.03, \mathrm{p}=0.92)$.

\section{Data analyses}

We analysed various datasets separately: detritivores, all litter invertebrates (detritivores plus other invertebrates), and four orders of insects - the Ephemeroptera, Trichoptera, Diptera and Coleoptera - which occurred in 11 of the 15 study regions. Other orders occurred in too few regions for analyses of latitudinal gradients. Two regions (French Guiana, Kenya) were excluded from the analyses of 'detritivores' because occurrences were extremely low, with only two species occurring in some of the streams; and we did not have data for 'all litter invertebrates' for three regions (Maryland, Malaysia, Queensland). We present results for detritivores in the main results section and for all litter invertebrates and taxonomic orders as Supplementary material Appendix 1. We examined $\alpha$-, $\gamma$ - and $\beta$-diversity, the latter using several measures: multiplicative $\left(\beta_{\mathrm{m}}=\gamma / \alpha_{\mathrm{m}}\right)$, additive $\left(\beta_{\mathrm{a}}=\gamma-\alpha_{\mathrm{m}}\right)$, beta partition $\left(\beta_{\mathrm{p}}=1-\alpha_{\mathrm{m}} / \gamma\right)$ and Jost partitioning $\left(\beta_{\mathrm{J}}\right)$ (Jost 2007, Baselga 2010, Kraft et al. 2011).

We tested hypotheses $\mathrm{H} 1-\mathrm{H} 4$ by examining latitudinal changes in measures that reflect nestedness, dispersal, environmental filtering and competition for the detritivore dataset. To test H1, we examined two nestedness estimators (see below). $\mathrm{H} 2$ was examined through the relationship between assemblage compositional similarity and distance between (a)

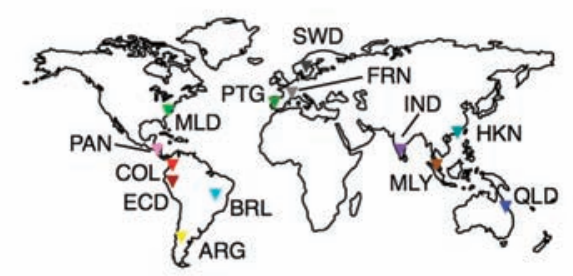

(b)

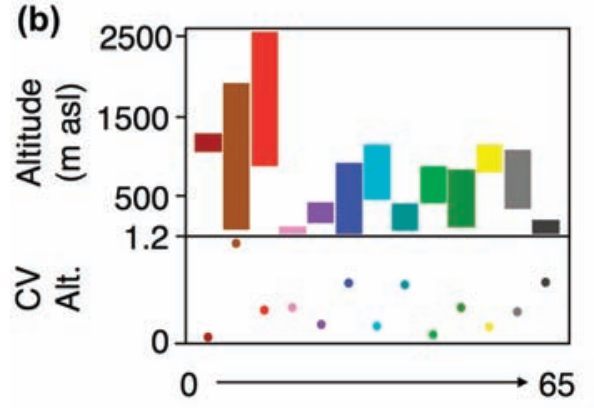

(c)

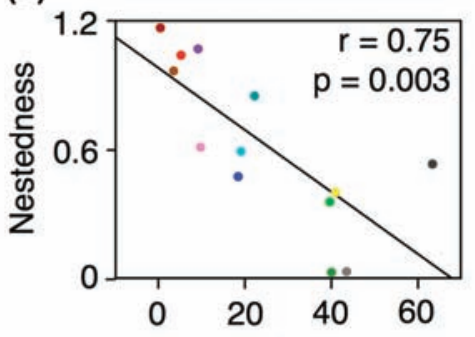

(d)

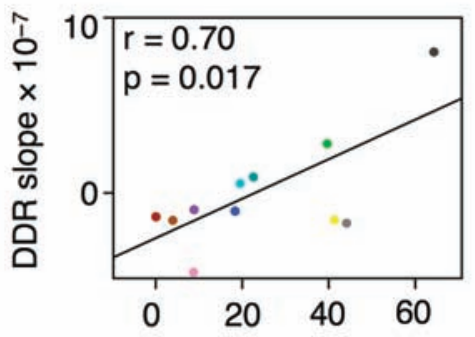

(e)

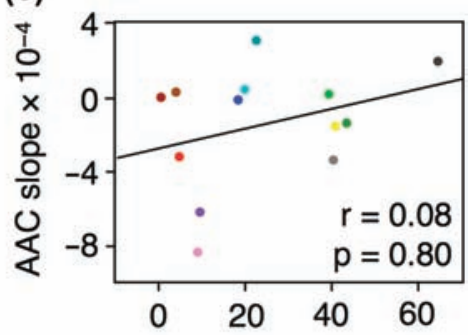

(f)

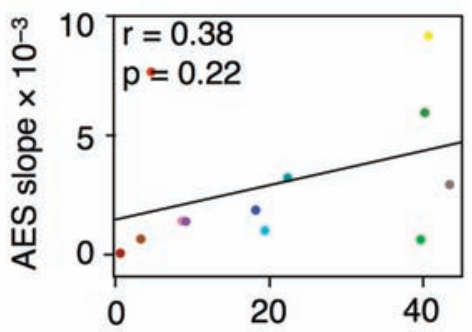

Absolute latitude (degrees from equator)

Figure 1. Latitudinal change in ecological processes potentially structuring stream detritivore assemblages: (a) map of study regions; (b) altitudinal range and coefficient of variation in each region; (c-f) latitudinal change in nestedness of assemblages (WINE, based on abundances), the slope of the distance-decay relationship (DDR), the slope of the relationship between assemblage similarity and altitudinal distance (AAC), and the slope of the relationship between assemblage similarity and environmental similarity (AES), respectively. ARG, Argentina; BRL, Brazil; COL, Colombia; ECD, Ecuador; FRN, France; HKN, Hong Kong; IND, India; MLD, Maryland, United States; MLY, Malaysia; PAN, Panama; PTG, Portugal; QLD, Queensland, Australia; SWD, Sweden. 
Table 1. Study regions (ordered by absolute latitude), region codes, number of sites sampled in each region, mean latitude and latitudinal range (absolute degrees), mean distance between sites $(\mathrm{km})$, local diversity $\left(\alpha_{\mathrm{m}}=\right.$ mean number of species per site) and regional diversity $(\gamma=$ number of species per region) of litter-consuming detritivores and all leaf litter-associated invertebrates.

\begin{tabular}{|c|c|c|c|c|c|c|c|c|c|}
\hline \multirow[b]{2}{*}{ Region } & \multirow[b]{2}{*}{ Code } & \multirow[b]{2}{*}{ No. of sites } & \multirow[b]{2}{*}{ Mean latitude } & \multirow{2}{*}{$\begin{array}{l}\text { Latitudinal } \\
\text { range }\end{array}$} & \multirow{2}{*}{$\begin{array}{c}\text { Mean } \\
\text { distance }\end{array}$} & \multicolumn{2}{|c|}{ Detritivores } & \multicolumn{2}{|c|}{ All invertebrates } \\
\hline & & & & & & $\alpha_{\mathrm{m}}$ & $\gamma$ & $\alpha_{m}$ & $\gamma$ \\
\hline Ecuador & ECD & 10 & 0.10 & $0.09-0.13$ & 1.5 & 8.0 & 16 & 46.4 & 131 \\
\hline Kenya & KEN & 10 & 0.18 & $0.03-0.39$ & 133.2 & - & - & 11.2 & 25 \\
\hline Malaysia & MLY & 12 & 4.02 & $3.23-4.50$ & 334.5 & 5.8 & 22 & - & - \\
\hline Colombia & $\mathrm{COL}$ & 9 & 4.78 & $4.71-4.89$ & 24.5 & 6.6 & 12 & 43.2 & 134 \\
\hline French Guiana & FGN & 10 & 5.14 & $5.06-5.29$ & 17.6 & - & - & 2.8 & 20 \\
\hline Panama & PAN & 10 & 8.95 & $10.41-10.44$ & 166.5 & 1.5 & 3 & 41.7 & 102 \\
\hline India & IND & 10 & 9.21 & 8.18-11.60 & 256.8 & 5.2 & 7 & 19.6 & 50 \\
\hline Queensland & QLD & 10 & 18.08 & $17.24-19.01$ & 97.3 & 6.6 & 15 & - & - \\
\hline Brazil & $\mathrm{BRL}$ & 10 & 19.44 & 18.05-20.50 & 130.8 & 2.2 & 3 & 33.4 & 60 \\
\hline Hong Kong & $\mathrm{HKN}$ & 10 & 22.24 & $22.16-22.30$ & 13.0 & 3.6 & 8 & 41.5 & 54 \\
\hline Maryland & MLD & 10 & 39.60 & $39.36-39.71$ & 22.9 & 4.2 & 13 & - & - \\
\hline Portugal & PTG & 10 & 40.27 & $40.07-40.60$ & 30.7 & 8.7 & 14 & 21.7 & 46 \\
\hline Argentina & ARG & 10 & 40.99 & $40.47-41.26$ & 166.8 & 6.2 & 11 & 26.8 & 67 \\
\hline France & FRN & 10 & 43.43 & $43.39-43.49$ & 15.8 & 7.4 & 10 & 30.8 & 55 \\
\hline Sweden & SWD & 11 & 64.09 & $63.56-64.39$ & 45.9 & 8.2 & 19 & 23.2 & 63 \\
\hline
\end{tabular}

sites (i.e. distance-decay relationship, DDR) and the relationship between assemblage similarity and altitudinal range (AAC). To test $\mathrm{H} 3$ we used the relationship between assemblage similarity and environmental similarity (AES). H4 was tested through species co-occurrences (C-score). To test $\mathrm{H} 5$ we examined the same metrics for all litter invertebrates and separate taxa. The calculation of each metric was as follows.

Nestedness. For each region we compiled a speciesby-site matrix, using the number of individuals of each species at each site. We calculated the level of nestedness using two approaches: the weighted-interaction nestedness estimator for abundance matrices (WINE) (Galeano et al. 2009), using the R library 'bipartite' ('wine' function), and the nestedness based on overlap and decreasing fill for presence/absence matrices (NODF) (Almeida-Neto et al. 2008), using Aninhado 3.0.3 (null model CE). Since nestedness measures are sensitive to matrix size (Ulrich et al. 2009), random matrices were generated from null models to calculate z-scores for significance tests (Gotelli 2000), and normalized values ([observed value-mean]/[max-mean]) were used for cross-region comparisons (Guimarães and Guimarães 2006, Galeano et al. 2009).

DDR slope. For each region, we calculated Euclidean distances between pairs of sites (based on UTM coordinates), and the degree of similarity of their assemblages using the Bray-Curtis index of similarity using the R library 'vegan' ('vegdist' function). The slope of the linear regression between distances and assemblage similarities was used as a measure of dispersal limitation (Soininen et al. 2007, Brown and Swan 2010).

AAC slope. For each region, we assessed the altitudinal distance (in $\mathrm{m}$ ) between pairs of sites. We related altitudinal distances to assemblage similarities with linear regression, and the slope was used as a measure of dispersal across altitudinal gradients.

AES slope. For each region, we assessed the environmental similarity between pairs of sites with a multivariate representation of environmental variables (Clark and Ainsworth 1993) in the R library 'simba' ('bioenv' function). Then, Euclidean distances were calculated between pairs of sites for all possible subsets of environmental variables, standardized to unit standard deviation. The rank correlation was calculated between assemblage dissimilarity (using the Bray-Curtis index) and environmental similarity (measured as Euclidean distance in multivariate space). The subset of environmental variables with the highest rank correlation was retained. The AES slope was estimated as the slope of the best-fit line relating assemblage similarity and environmental distance, calculated for those variables retained, for all pairwise combinations of sites. To satisfy the assumption of no spatial structure in environmental variables (Chase and Myers 2011), we found no significant correlation between inter-site distance and environmental distance within a region.

C-score. Using the C-score as the test statistic, we measured species co-occurrences in the presence/absence matrix (the 'checkerboard') (Stone and Roberts 1990). The C-score measures the number of checkerboard subunits, which occur when species $A$ is present at site 1 , and absent at site 2 , while the reverse is true for species $\mathrm{B}$. The $\mathrm{C}$-score is the average number of subunits between all possible species pairs, and an observed C-score greater than expected by chance indicates that co-occurrences are less than expected by chance (i.e. species are segregated; often a signal of competition), whereas a score lower than expected by chance is indicative of spatial association. We used a one-tailed z-test to assess the significance of the difference between observed and expected $\mathrm{C}$-scores, and the metric of the z-test (i.e. the z-score) for depicting the potential latitudinal trend of co-occurrence, (null model with fixed margins of the species-by-site matrices in Mathematica 8.0). While patterns of co-occurrence might be caused by environmental preferences, association or segregation of species within one functional group indicates either the potential for competition or avoidance of competition by niche differentiation.

Latitudinal variation of all these metrics (nestedness indices, DDR, AAC and AES slopes, and C-score) was estimated with linear regression using both absolute latitude and latitude corrected to remove the effect of inter-regional differences in altitudinal ranges (Fig. 1b). The latter was calculated 
Table 2. Nestedness index (WINE, based on abundances); slopes of the relationships between assemblage similarity and distance between sites (DDR), between assemblage similarity and altitudinal change (AAC), and between assemblage similarity and environmental similarity (AES); and C-score quantifying species co-occurrences, for leaf-consuming detritivore assemblages in each study region (codes are given in Table 1). Asterisks indicate significant results $\left({ }^{* * *} \mathrm{p}<0.001 ;{ }^{* *} \mathrm{p}<0.001 ;{ }^{*} \mathrm{p}<0.05\right.$; ns, not significant); (o) indicate outliers that were removed from regression analyses based on Cook's distance.

\begin{tabular}{|c|c|c|c|c|c|c|c|c|c|c|}
\hline \multirow{2}{*}{$\frac{\text { Region }}{\text { ECD }}$} & \multicolumn{2}{|c|}{ Nestedness } & \multicolumn{2}{|c|}{ DDR slope $\left(\times 10^{-7}\right)$} & \multicolumn{2}{|c|}{ AAC slope $\left(\times 10^{-4}\right)$} & \multicolumn{2}{|c|}{ AES slope $\left(\times 10^{-3}\right)$} & \multicolumn{2}{|c|}{ C-score } \\
\hline & 1.08 & $* * *$ & -1.36 & ns & -0.05 & $*$ & 0.00 & ns & -0.01 & $\mathrm{~ns}$ \\
\hline MLY & 0.91 & $* * *$ & -1.57 & $*$ & 0.16 & ns & 0.57 & $*$ & 0.54 & $*$ \\
\hline $\mathrm{COL}$ & 0.97 & $* * *$ & -76.29 & $* * *(\mathrm{o})$ & -3.20 & $* * *$ & 7.67 & $* * *$ & 0.28 & ns \\
\hline PAN & 0.62 & $* *$ & -4.64 & ns & -8.37 & ns & 1.39 & ns & 0.13 & $\mathrm{~ns}$ \\
\hline IND & 0.99 & $* * *$ & -0.95 & ns & -6.26 & ns & 1.35 & ns & -0.08 & ns \\
\hline QLD & 0.50 & $*$ & -1.01 & ns & -0.22 & ns & 1.81 & ns & 0.06 & ns \\
\hline BRL & 0.60 & $*$ & 0.55 & ns & 0.54 & ns & 0.89 & ns & - & - \\
\hline HKN & 0.81 & $* *$ & 0.95 & ns & 3.11 & ns & 3.09 & $* *$ & -0.02 & ns \\
\hline MLD & 0.41 & ns & 2.82 & ns & 0.08 & ns & 0.48 & ns & -0.17 & $\mathrm{~ns}$ \\
\hline PTG & 0.13 & ns & -20.40 & $*(\mathrm{o})$ & -3.23 & $* *$ & 5.97 & ns & -0.01 & ns \\
\hline ARG & 0.44 & ns & -1.57 & ns & -1.70 & ns & 9.19 & $*$ & 0.21 & ns \\
\hline FRN & 0.13 & ns & -1.70 & ns & -1.36 & ns & 2.91 & $* *$ & -0.02 & $\mathrm{~ns}$ \\
\hline SWD & 0.55 & $*$ & 8.11 & $\mathrm{~ns}$ & 1.87 & ns & 93.31 & $* *(o)$ & 0.42 & $*$ \\
\hline
\end{tabular}

using the residuals of the latitude vs. altitudinal range linear regression (latitude $=25.588-0.007 \times$ altitudinal range; $r=0.20, \mathrm{p}=0.47)$. The relationship between latitude and the residuals of the latitude vs. altitudinal range regression was: latitude $=21.323+$ residuals $(r=0.98, \mathrm{p}<0.0001)$. We removed outliers based on Cook's distance (Cook 1977): values higher than $4 /(\mathrm{n}-\mathrm{k}-1)$ were removed, where $\mathrm{n}$ is the number of replicates and $\mathrm{k}$ is the number of variables in the model ( $=1$ in all cases). This procedure was repeated until no more outliers were found, which rendered three outliers (two DDR, one AES) from the detritivore relationships (Table 2), and five outliers (three DDR, two AES) from the relationships for all litter invertebrates (Supplementary material Appendix 1, Table A2).

\section{Results}

We found that nestedness of detritivore assemblages was significant in all tropical regions and declined steadily with increasing latitude (Table 2) (absolute latitude: WINE, $r=0.75, \mathrm{p}=0.003$; NODF, $r=0.85, \mathrm{p}=0.002$; corrected latitude: WINE, $r=0.75, \mathrm{p}=0.003$; NODF, $r=0.82$, $\mathrm{p}=0.002$ ) (Fig. 1c). This supported our hypothesis H1 that many species-poor tropical assemblages are nested subsets of richer assemblages. Our first proposed explanation for this pattern was that dispersal was limited in the tropics. DDRs were not significant within most regions (Table 2), suggesting that dispersal was not a major structuring force of detritivore assemblages at the regional scale. However, we found that the magnitude of the DDR slopes increased with latitude (absolute latitude: $r=0.70, \mathrm{p}=0.017$; corrected latitude: $r=0.67, \mathrm{p}=0.025)$ (Fig. 1d), supporting our hypothesis $\mathrm{H} 2$ that dispersal is less important in the tropics than at higher latitudes. We predicted that dispersal would be limited in tropical regions in relation to low climate overlap across altitudes, but this was not supported by our analyses. The relationships between assemblage similarity and AAC were significant for only two tropical regions and one temperate region (Table 2), and the slope of the AAC relation- ship showed no latitudinal trend (absolute latitude: $r=0.08$, $\mathrm{p}=0.80$; corrected latitude: $r=0.009, \mathrm{p}=0.98)$ (Fig. 1e).

We further hypothesized that higher nestedness in the tropics could be linked to stronger environmental filtering. The AES relationship was significant for many regions (Table 2), suggesting that environmental filtering was in fact an important structuring agent of detritivore assemblages. However, contrary to hypothesis $\mathrm{H} 3$, the AES slope did not decrease with latitude (absolute latitude: $r=0.38, \mathrm{p}=0.22$; corrected latitude: $r=0.47, \mathrm{p}=0.12$ ) (Fig. 1f). The environmental factors most related to assemblage composition within regions were leaf litter availability (reflecting the strong dependence of detritivores on this resource), water chemistry (mostly $\mathrm{pH}$, alkalinity and conductivity, which influence rates of litter breakdown) (Webster and Benfield 1986), channel size and morphology (which affect leaf litter retention) (Lepori et al. 2005), and water temperature (which is also a major driver of detritivore diversity across latitudes - Boyero et al. 2012) (Supplementary material Appendix 1, Table A3).

Finally, we hypothesised that there would be reduced competition in the tropics, although this might be countered by competition for good-quality leaf litter. In most cases there was no such relationship as C-scores did not differ from a random model (Table 2), nor did they change systematically with latitude (absolute latitude: $r=0.02, \mathrm{p}=0.95$; corrected latitude: $r=0.11, \mathrm{p}=0.73$ ). When we examined all these ecological patterns and processes for the whole invertebrate assemblage or selected insect orders we found no latitudinal variation in any of them, which supported our hypothesis H5 (Supplementary material Appendix 1).

\section{Discussion}

Our results indicate that, as we predicted, stream detritivore assemblages are structured differently across latitudinal gradients. Tropical regions show a nested structure, where species-poor assemblages contain subsets of species found at species-rich sites, while no nested structure is evident at higher latitudes. Interestingly, other studies have reported 
that stream invertebrate assemblages at high latitudes are nested, but unlike our detritivore-only analysis, have been concerned with whole assemblages (Heino et al. 2009). We initially hypothesized that a latitudinal decrease in nestedness of the assemblages could be related to one or several of the following trends towards higher latitudes: increased dispersal capacity, reduced environmental filtering, or stronger competition between species. We found no evidence that biological interactions were important in structuring detritivore assemblages, but differences between tropical and temperate assemblages could be explained by a combination of the other two processes: environmental filtering and dispersal.

Environmental filtering appeared to be the primary structuring process of stream detritivore assemblages in most of our study regions. Environmental factors act as filters that determine which species from the regional species pool can occur at a given site (Boyero et al. 2011b, Chase and Myers 2011), so a site with few filters is occupied by both common and rare species, while only those species that can cross most filters (i.e. generalists) are widespread. This nested structure is evident for detritivore assemblages in the tropics, but disappears towards higher latitudes with, we suggest, increase in species' dispersal. Although dispersal is not regarded as a major structuring force in invertebrate assemblages in small, temperate streams (Brown and Swan 2010), and it can vary substantially among taxa (Gronroos et al. 2013), we found an increase in dispersal towards higher latitudes that may disrupt the nested structure and lead to local assemblages that are non-nested subsets of regional pools.

Reduced dispersal towards the tropics was not explained by the reduced altitudinal range shifts proposed by Janzen's (1967) hypothesis. Altitude did not limit dispersal everywhere in the tropics, although we note that different altitudinal ranges were sampled in each region in this study (Fig. 1b). An alternative explanation for the broader distributions in temperate regions is that their greater seasonality and climatic variability represent a major selective force for dispersal (Roy and Goldberg 2007, Willis et al. 2007). The species that occur in previously glaciated regions are the ones capable of dispersing there. No such capacity has generally been required of species in the tropics, except perhaps in habitats of limited extent in which population fluctuations due to climatic variability might have resulted in local extinctions (Williams and Pearson 1997). Moreover, tropical forests are generally denser than high-latitude forests, which may further limit the ability of the terrestrial adults of some aquatic insects to disperse overland (Krosch et al. 2009).

In summary, our global-scale analysis suggests that, from low to high latitudes, the ecological mechanisms underlying the composition and diversity of detritivore assemblages in streams appear to shift from mainly deterministic (environmental filtering) to mainly stochastic (dispersal), providing an explanation for their unusual pattern of local diversity increasing with latitude (Boyero et al. 2012). This is in agreement with previous findings that both deterministic and stochastic processes operate to shape species assemblages (Strange et al. 1992, Hui et al. 2013) but their relative importance can vary across ecological gradients (Chase and Myers 2011). In the tropics, strong environmental filtering together with species' lower dispersal results in generally species-poor local assemblages, which are nested subsets of less common richer assemblages. At higher latitudes, many taxa have greater dispersal abilities thereby disrupting the nested structure, leading to species-rich local assemblages that occur as non-nested subsets of the regional species pool. Our results match those of Myers et al. (2013) for woody plants of one temperate and one tropical forest. They found that mechanisms driving diversity and community assembly varied with latitude, with dispersal limitation playing a key role in the tropical forest, and environmental filters being important in the temperate forest. Our study, across 149 sites in 15 regions, appears to be the first one to report such patterns in animals.

The patterns we identified may not be detected in studies of entire animal assemblages, or of selected taxa that comprise more than a single functional group. Our analyses of the entire assemblage and of four abundant insect orders indicated no latitudinal variation in $\alpha$-diversity or the different ecological mechanisms explored here for whole leaf-litter invertebrate assemblages. Individual insect orders showed decreasing $\alpha$ diversity with latitude, but none showed latitudinal change for any of the metrics used to quantify ecological processes. Thus, seeking latitudinal patterns within functional groups provided insights that were not evident from changes in total stream invertebrate assemblages or individual taxa. These patterns need to be explored for other functional groups and in other habitats, because stream detritivores show an unusual latitudinal diversity gradient (Boyero et al. 2011a, 2012), although some freshwater taxa show more usual trends (Vinson and Hawkins 2003, Pearson and Boyero 2009). Our results suggest that a shift in approach from taxon-based to function-based investigations for animal assemblages may help elucidate the mechanisms behind large-scale gradients in diversity.

Analyses of empirical data such as those presented here cannot unequivocally demonstrate the mechanisms that drive the patterns observed, nor can we be certain that we have included all plausible mechanisms. This can be achieved only through experimental work, which is difficult to conduct at the global scale. However, our results point to a latitudinal shift in ecological drivers of diversity that merits further investigation. Our findings may have broad implications for conservation science and management, as they suggest the need for varying the scale of protected areas at different latitudes. Thus, for stream detritivores, a key priority in the tropics should be the conservation of species-rich sites, whereas in temperate and boreal zones broad regional conservation efforts are more likely to be effective.

Acknowledgements - We thank the numerous assistants who helped with field and laboratory work. The study was funded by a grant from the National Geographic Society's Committee for Research and Exploration (grant number 7980-06 to LB) and various national funding sources, including MINECO's project CGL201016285 to LB. We thank M. Araújo, J. Heino and S. Milesi for constructive comments on the manuscript. Author contributions: LB conceived and coordinated the study; all authors collected data and/or contributed to the study design and methodology; LB, RGP, $\mathrm{CMS}$ and $\mathrm{CH}$ conceived the paper, analysed the data and wrote the paper, with input from other authors (listed in alphabetical order).

\section{References}

Almeida-Neto, M. et al. 2008. A consistent metric for nestedness analysis in ecological systems: reconciling concept and measurement. - Oikos 117: 1227-1239. 
Bascompte, J. et al. 2003. The nested assembly of plant-animal mutualistic networks. - Proc. Natl Acad. Sci. USA 100: 9383-9387.

Baselga, A. 2010. Partitioning the turnover and nestedness components of beta diversity. - Global Ecol. Biogeogr. 19: 134-143.

Bastian, M. et al. 2008. Effects of diversity loss on ecosystem function across trophic levels and ecosystems: a test in a detritusbased tropical food web. - Austral Ecol. 33: 301-306.

Bastolla, U. et al. 2009. The architecture of mutualistic networks minimizes competition and increases biodiversity. - Nature 458: $1018-1020$.

Boyero, L. et al. 2006. Leaf breakdown in tropical streams: the role of different species in ecosystem functioning. - Arch. Hydrobiol. 166: 453-466.

Boyero, L. et al. 2011a. Global distribution of a key trophic guild contrasts with common latitudinal diversity patterns. - Ecology 92: 1839-1848.

Boyero, L. et al. 2011b. A global experiment suggests climate warming will not accelerate litter decomposition in streams but may reduce carbon sequestration - Ecol. Lett. 14: 289-294.

Boyero, L. et al. 2012. Global patterns of stream detritivore distribution: implications for biodiversity loss in changing climates. - Global Ecol. Biogeogr. 21: 134-141.

Brown, B. L. and Swan, C. M. 2010. Dendritic network structure constrains metacommunity properties in riverine ecosystems. - J. Anim. Ecol. 79: 571-580.

Chase, J. M. and Myers, J. A. 2011. Disentangling the importance of ecological niches from stochastic processes across scales. - Phil. Trans. R. Soc. B 366: 2351-2363.

Clark, K. R. and Ainsworth, M. 1993. A method of linking multivariate community structure to environmental variables. - Mar. Ecol. Prog. Ser. 92: 205-219.

Cook, R. D. 1977. Detection of influential observations in linear regression. - Technometrics 15: 173-177.

Cummins, K. W. and Klug, M. J. 1979. Feeding ecology of stream invertebrates. - Annu. Rev. Ecol. Syst. 10: 147-172.

Galeano, J. et al. 2009. Weighted-interaction nestedness estimator (WINE): a new estimator to calculate over frequency matrices. - Environ. Model. Softw. 24: 1342-1346.

Gessner, M. O. et al. 2010. Diversity meets decomposition. - Trends Ecol. Evol. 25: 372-380.

Gotelli, N. J. 2000. Null model analysis of species co-occurrence patterns. - Ecology 81: 2606-2621.

Gronroos, M. et al. 2013. Metacommunity structuring in stream networks: roles of dispersal mode, distance type, and regional environmental context. - Ecol. Evol. 3: 4473-4487.

Guimarães, P. and Guimarães, P. R. J. 2006. Improving the analyses of nestedness for large sets of matrices. - Environ. Model. Softw. 21: 1512-1513.

Heard, S. B. 1994. Processing chain ecology: resource condition and interspecific interactions. - J. Anim. Ecol. 63: 451-464.

Heino, J. et al. 2009. Temporal variability of nestedness and idiosyncratic species in stream insect assemblages. - Divers. Distrib. 15: 198-206.

Hillebrand, H. 2004. On the generality of the latitudinal diversity gradient. - Am. Nat. 163: 192-211.

Hui, C. et al. 2013. Increasing functional modularity with residence time in the co-distribution of native and introduced vascular plants. - Nat. Commun. 4: 2454.

Janzen, D. H. 1967. Why mountain passes are higher in the tropics. - Am. Nat. 101: 233-249.

Jost, L. 2007. Partitioning diversity into independent alpha and beta components. - Ecology 88: 2427-2439.

Kadmon, R. 1995. Nested species subsets and geographic isolation: a case study. - Ecology 76: 458-465.
Kozak, K. H. and Wiens, J. J. 2007. Climatic zonation drives latitudinal variation in speciation mechanisms. - Proc. R. Soc. B 274: 2995-3003.

Kraft, N. J. B. et al. 2011. Disentangling the drivers of diversity along latitudinal and elevational gradients. - Science 333: 1755-1758.

Krosch, M. N. et al. 2009. Deeply divergent mitochondrial lineages reveal patterns of local endemism in chironomids of the Australian wet tropics. - Austral Ecol. 34: 317-328.

Lepori, F. et al. 2005. Does restoration of structural heterogeneity in streams enhance fish and macroinvertebrate diversity? Ecol. Appl. 15: 2060-2071.

McKie, B. G. and Malmqvist, B. 2009. Assessing ecosystem functioning in streams affected by forest management: increased leaf decomposition occurs without changes to the composition of benthic assemblages. - Freshw. Biol. 254: 2086-2100.

Myers, J. A. et al. 2013. Beta-diversity in temperate and tropical forests reflects dissimilar mechanisms of community assembly. - Ecol. Lett. 16: 151-157.

Pearson, R. G. and Boyero, L. 2009. Gradients in regional diversity of freshwater taxa. - J. N. Am. Benthol. Soc. 28: 504-514.

Pianka, E. R. 1966. Latitudinal gradients in species diversity: a review of concepts. - Am. Nat. 100: 33-46.

Ramírez, A. Gutiérrez-Fonscca, P. E. 2014. Functional feeding groups of aquatic insect families in Latin America: a critical analysis and review of existing literature. - Rev. Biol. Trop. 62: $155-167$.

Roy, K. and Goldberg, E. E. 2007. Origination, extinction, and dispersal: integrative models for understanding present-day diversity gradient. - Am. Nat. 170: S71-S85.

Soininen, J. et al. 2007. The distance decay of similarity in ecological communities. - Ecography 30: 3-12.

Stone, L. and Roberts, A. 1990. The checkerboard score and species distributions. - Oecologia 85: 74-79.

Strange, E. M. et al. 1992. Interactions between stochastic and deterministic processes in stream fish community assembly. - Environ. Biol. Fish. 36: 1-15.

Swan, C. M. et al. 2009. Identifying the relative importance of leaf versus shredder species loss on litter decomposition in streams. - Int. Rev. Hydrobiol. 94: 452-471.

Ulrich, W. et al. 2009. A consumer's guide to nestedness analysis. - Oikos 118: 3-17.

Vinson, M. R. and Hawkins, C. P. 2003. Broad-scale geographical patterns in local stream insect genera richness. - Ecography 26: 751-767.

Wallace, J. et al. 1997. Multiple trophic levels of a forest stream linked to terrestrial litter inputs. - Science 277: 102-104.

Webster, J. R. and Benfield, E. F. 1986. Vascular plant breakdown in freshwater ecosystems. - Annu. Rev. Ecol. Syst. 17: 567-594.

Williams, S. E. and Pearson, R. G. 1997. Historical rainforest contractions, localized extinctions and patterns of vertebrate endemism in the rainforests of Australia's wet tropics. - Proc. R. Soc. B 264: 709-716.

Willig, M. R. et al. 2003. Latitudinal gradients of biodiversity: pattern, process, scale, and synthesis. - Annu. Rev. Ecol. Evol. Syst. 34: 273-309.

Willis, K. J. et al. 2007. Testing the impact of climate variability on European plant diversity: 320000 years of water-energy dynamics and its long-term influence on plant taxonomic richness. - Ecol. Lett. 10: 673-679.

Wright, D. H. and Reeves, J. H. 1992. On the meaning and measurement of nestedness of species assemblages. - Oecologia 92: 416-428. 